\title{
Impacts of polycyclic aromatic hydrocarbons from vehicular activities on the ambient air quality of Lagos mega city
}

\author{
Bamidele Sunday Fakinle ${ }^{1}$ Ebenezer Leke Odekanle ${ }^{2}$ Abiodun Paul Olalekan ${ }^{3}$ \\ Olayemi AbosedeOdunlami ${ }^{4}$ Jacob Ademola Sonibare ${ }^{2}$ \\ ${ }^{1}$ Department of Chemical Engineering, Landmark University, Omu-Aran, Nigeria \\ 2Environmental Research Laboratory, Department of Chemical Engineering, \\ Obafemi AwolowoUniversity, Ile Ife,Nigeria \\ ${ }^{3}$ Department of Chemical and Petroleum Engineering, University of Lagos, Akoka, \\ Lagos State, Nigeria \\ ${ }^{4}$ Department of Chemical Engineering, Covenant University, Ota, Ogun State, \\ Nigeria
}

\begin{abstract}
In response to the growing concern about the contribution of polycyclic aromatic hydrocarbons (PAHs) from vehicular activities in Lagos mega city and their effect on air quality, PAH emissions were estimated using the emission factors approach. To make these estimates, PAH emission factors were calculated from the profile ratio of four PAHs emitted from vehicle sources obtained from the European Environment Agency's emission inventory guidebook, whereas the total number of registered vehicles based on the type of fuel they use for a period of 10 years was obtained from Lagos State Bureau of Statistics. Vehicle emissions were estimated using a combination of individual emission factors, the total number of vehicles in use based on fuel type, and the average mileage covered. The average highest level of emission of PAHs of 3.542 kilograms $(\mathrm{kg})$ for gasoline-powered vehicles was obtained in 2013, whereas the average lowest level of emission of

$2.679 \mathrm{~kg}$ was recorded for diesel-powered vehicles in 2007. In the same manner, 2013 had highest annual average total emission of $6.384 \mathrm{~kg}$, whereas the lowest annual total PAHs emission of $5.727 \mathrm{~kg}$ was recorded in 2007. It is therefore advised that effective control measure should be put in place by regulatory agency to prevent personnel exposure to these hazardous substances.
\end{abstract}

KEYWORDS

air quality, PAHs, pollution, vehicular activities

\section{Correspondence}

Bamidele Sunday Fakinle, Department of Chemical Engineering, Landmark University, Omu-Aran, Nigeria.

Email:xdales@yahoo.com

Environmental Quality Management. 2018;27:73-78. 